\title{
Pharmacokinetic Study of a Capsule-based Chronomodulated Drug Delivery System of Salbutamol Sulphate in Rabbits
}

\author{
Mohd Javed Qureshi ${ }^{1,2}$, Javed Ali ${ }^{1}$, Sanjula Baboota ${ }^{1}$, Alka Ahuja ${ }^{1}$ and Chitneni \\ Mallikarjun $^{3}$ \\ ${ }^{1}$ Department of Pharmaceutical Technology, School of Pharmacy, Taylor's University, Lakeside Campus, Selangor Malaysia, ${ }^{2}$ \\ Department of Pharmaceutics, Jamia Hamdard (Hamdard University), New Delhi, India, ${ }^{3}$ Department of Pharmaceutical \\ Technology, International Medical University, Kuala Lumpur, Malaysia.
}

*For correspondence: Email: Mohd.Javed@taylors.edu.my

\begin{abstract}
Purpose: To develop and determine the in vivo performance of a capsule-based pulsatile drug delivery system containing salbutamol sulphate

Methods: A controlled pulsatile release of drug after a programmed $4 \mathrm{~h}$ lag period was achieved from cross-linked gelatin capsule shells containing salbutamol pellets, and sealed with a suitable mixture of sodium alginate and ethyl cellulose as plug. In order to confirm the utility of developed system for the management of nocturnal asthma, a crossover study was conducted. six male rabbits were fasted overnight and divided into two groups comprised of 3 rabbits each. The individual rabbits were administered the developed pulsatile capsule and immediate release salbutamol capsule as reference, separately. Blood samples were collected from the ear vein of the animals into heparinized tubes and used to determine pharmacokinetic parameters, namely, maximum plasma concentration $\left(C_{\text {max }}\right)$, time to reach maximum plasma concentration $\left(T_{\max }\right)$, and area under the plasma concentration - time curve $(A \cup C 0-\infty)$ using a validated HPLC method.

Results: It was observed that drug release from the optimized time-controlled capsule stopped for a period of approximately $4.25 \mathrm{~h}$ with an average $C_{\max }$ and $T_{\max }$ of $271.54 \pm 58.95 \mathrm{ng} / \mathrm{ml}$ and $6.00 \pm 0.25$ $h$. The $A \cup C_{0-\infty}$ of salbutamol after administration of the time-controlled pulsatile system was $2494.73 \pm$ $525.95 \mathrm{ng} \mathrm{h} / \mathrm{ml}$ while that of the immediate-release formulation was $2352.77 \pm 432.51 \mathrm{ng} \mathrm{h} / \mathrm{ml}$. Using ANOVA at a significant difference of $p<0.05$ (CI 95\%), there was no significant difference for the $A \cup C_{0}$ $\infty$ between immediate release and the pulsatile capsule developed.

Conclusion: The developed system is capable of releasing salbutamol after a $4 \mathrm{~h}$ lag period and can be considered as promising delivery system for time-controlled (pulsatile) delivery of the medication for the management of nocturnal asthma.
\end{abstract}

Keywords: $\mathrm{pH}$-controlled release, Lag time, Pulsatile release, Hydrocolloid plug, Nocturnal asthma.

Tropical Journal of Pharmaceutical Research is indexed by Science Citation Index (SciSearch), Scopus, International Pharmaceutical Abstract, Chemical Abstracts, Embase, Index Copernicus, EBSCO, African Index Medicus, JournalSeek, Journal Citation Reports/Science Edition, Directory of Open Access Journals (DOAJ), African Journal Online, Bioline International, Open-J-Gate and Pharmacy Abstracts

\section{INTRODUCTION}

Up till the early 1990s, efforts were mainly to design drug delivery systems which will release the drug at fairly constant rate. In fact, these systems turned to be one of the most successful systems in delivering the drug molecule [1]. But still for many of the drugs, use of such systems is not suitable because of a number of reasons. This is particularly true in cases where the drug is subjected to large metabolic degradation. Due 
to 'first pass effect' there will be reduction in the bioavailability of the drug because gradual release can result in greater degradation. Secondly drugs with short half-life need to be administered repeatedly which results in patient non-compliance. Further, in the case of chronic treatment where the drug is given in sustained release dosage form, continuous exposure of the drug to body may lead to adverse effect. Lastly, drugs which exhibit tolerance should not be delivered at a constant rate, since the drug effect decreases with time at constant drug level. In such cases it is preferable to opt for a dosage form which will provide concentration of drug at particular time point only [2].

Chronopharmaceutics, whereby research is devoted to the design and evaluation of drug delivery systems that release a therapeutic agent at a rhythm that ideally matches the biological requirement of a given disease therapy, has attracted some attention in recent times [3,4]. The objective of this study was to determine the in vivo behavior of a developed salbutamol pulsatile capsule for the management of nocturnal asthma. Capsule is designed to have a release off period of 4 hour $[5,6]$. The developed system has already shown positive results during in vitro studies [7]. Ideally, an animal model that suitably mimics human physiological system should be chosen for in vivo studies. In this regard, animals such as monkeys, pigs and dogs have been suggested [9]. However, since these animals are difficult to handle, rabbit was chosen for use in the present study due to the ease of handling.

\section{EXPERIMENTAL}

\section{Materials}

Salbutamol sulphate (Ranbaxy Research Laboratories, Gurgaon, India), microcrystalline cellulose (Avicel PH101, Jubiliant Organosys, New Delhi India), Eudragit L 100 and S 100 (Rohm Pharma, GmbH Germany) Sodium alginate, HPMC, Polyethylene oxide, Ethylcellulose (Ranbaxy Research Laboratories, Gurgaon, India) were obtained as gifts from the indicated sources. Acetonitrile HPLC grade and methanol HPLC grade were purchased from JT Baker (USA). Salbutamol and standards were purchased from Sigma Aldrich (USA). All other chemicals used were of analytical grade

\section{Development of pulsatile drug delivery system}

The pulsatile capsule was aimed to provide a total lag time of approximately $4 \mathrm{~h}$. The basic design of the proposed dosage form consisted of an insoluble capsule body filled with drug loaded pellets sealed with hydrocolloid plug, and a soluble capsule cap. Hydrocolloid plug was inserted to stop the release of pellets for a period of $2 \mathrm{~h}$. The plugged capsule was further coated with enteric polymer (Eudragit S100: Eudragit L100, 4:1) to provide a additional 2 hour lag time and to minimize the gastric transit time variability. Finally, a total of 4-h lag time was achieved using hydrocolloid plug material together with outer enteric coating of sealed capsule. Enteric coating was expected to be dissolved at $\mathrm{pH}$ 6.8. Pellets were prepared by extrusion and spheronization using $2 \% \mathrm{w} / \mathrm{v}$ of PVP $\mathrm{K} 30$ as binder and water as granulating liquid. In order to prepare insoluble gelatin capsule bodies, the empty gelatin capsule bodies were exposed to formalin vapors generated by a reaction between $15 \% \mathrm{v} / \mathrm{v}$ formaldehyde solution and potassium permanganate. The caps of the capsules were not subjected to the above treatment, leaving them water soluble.

Rapidly disintegrating pellets were prepared by extrusion, spheronization method. Drug and excipients were preblended and sieved through $0.420 \mathrm{~mm}$ mesh screen. Ac DiSol (3\%w/w) as disintegrant and $2 \%$ PVP K-30 aqueous solution, as binding agent, were added to mixed powders to achieve proper consistency and kneaded properly. The pellets were evaluated for flow properties, surface morphology and in vitro dissolution behavior. Optimized pellets were filled in to insoluble capsule, plugged with hydrocolloid material to provide the desired delay in release and coated with enteric polymer which was required to be dissolved in $\mathrm{pH} 6.8$ to avoid gastric emptying variations [9].

The dissolution behavior of the developed system was studied in $\mathrm{pH} 1.2$ and phosphate buffer $\mathrm{pH} 6.8$ media. For the initial $2 \mathrm{~h}$, the system was exposed to $0.1 \mathrm{M} \mathrm{HCl}$ after that media was changed to $\mathrm{pH} 6.8$ phosphate buffer to simulate lower intestinal $\mathrm{pH}$.

After in-vitro optimization, in-vivo studies were carried out in healthy rabbits to validate the developed system. The calibration curves were constructed by spiking drug-free plasma with known amount of salbutamol at concentrations of $5.0-400.0 \mathrm{ng} / \mathrm{ml}$. The standard calibration curve ( $n=6$ ) was found to be linear over the concentration range used with a correlation coefficient of 0.9999. The samples were quantified using peak height ratio of salbutamol over the internal standard. 


\section{Animal studies}

The pharmacokinetic study was performed in accordance with the guidelines of the National Institutes of Health (10) and was approved by the Ethical Committee for Animal Experimentation of Hamdard University, India. The study was conducted using 6 male rabbits $(3.0$ - $3.5 \mathrm{~kg})$. The rabbits were fasted overnight for at least 12 $\mathrm{h}$ prior to the study. The 6 rabbits were divided into two groups with three rabbits in each group. In the first phase of the study, the rabbits in group 1 received optimized formulation and those in group 2 received immediate release capsule as reference. After a washout period of 7 days, the rabbits were crossed-over and administered the alternate formulation. Both optimized formulation and reference containing equivalent of $5 \mathrm{mg}$ of salbutamol sulphate were administered orally. The animals were fed $4 \mathrm{~h}$ after drug dosing and had free access to water throughout the study period. Blood samples of 2 $\mathrm{ml}$ were collected though the marginal ear vein into heparinized tubes at regular time intervals. Blood samples were centrifuged at 4,000 rpm (Labofuge 200, Germany) for $5 \mathrm{~min}$. The supernatant was transferred to empty glass tubes and stored at $-70{ }^{\circ} \mathrm{C}$ until further analysis.

Pharmacokinetic parameters, namely, maximum plasma concentration $\left(\mathrm{C}_{\max }\right)$, time to reach maximum plasma concentration $\left(T_{\max }\right)$, and area under the plasma concentration- time curve $(A \cup C 0-\infty)$, were obtained from plasma concentration versus time profiles. $\mathrm{C}_{\max }$ and $\mathrm{T}_{\max }$ were derived directly from the in vivo data. The area under the plasma salbutamol concentration time curve $\left(A \cup C_{0-t}\right)$ was calculated by the trapezoidal rule. $\mathrm{AUC}_{0-\infty}$ was the summation of area under plasma salbutamol concentrationtime curve from zero to time $t\left(A \cup C_{0-t}\right)$ and area under plasma salbutamol concentration-time curve from time t to infinity $\left(A \cup C_{t-\infty}\right)$. $A U C_{t-\infty}$ was calculated by dividing the last measurable plasma concentration with the terminal elimination rate constant $(\mathrm{Ke})$. The value of $\mathrm{Ke}$ was the slope of logarithmic transformation of the terminal plasma concentration-time curve

\section{Plasma treatment and determination of salbutamol concentration}

The method reported by Xiao-Li et al with a slight modification was used for the determination. Supelco LC-18 solid phase extraction (SPE) columns $(1 \mathrm{ml})$ were used for this purpose. The column was washed with methanol and water 1 $\mathrm{ml}$ each. The internal standard solution, bamethan $(0.2 \mu \mathrm{g} / \mathrm{ml})$ and $1 \mathrm{ml}$ of the plasma sample were passed into the column. After 2 min, mild suction was applied to allow the sample to pass through the column. The suction was increased to expel all the trapped liquid from the column. The column was washed with water three times followed by acetonitrile once. Then 2 $\mathrm{ml}$ methanol was passed through the column to elute the internal standard and the drug from the sorbent. The eluted liquid was dried at $40{ }^{\circ} \mathrm{C}$ under a gentle stream of nitrogen gas. The residue obtained was reconstituted with $50 \mu$ of mobile phase and $40 \mu \mathrm{l}$ was injected into the system [10].

The HPLC system comprised of Waters pump (Model 510, Milford, MA, USA) equipped with sample injection port (7725i Rheodyne, Cotati, California, USA) fitted with $50 \mu$ l sample loop, a RF- 10Axl fluorescence detector (Shimadzu, Tokyo, Japan) and Chromato-integrator (D-2500, Hitachi, Tokyo, Japan). The analytical column,

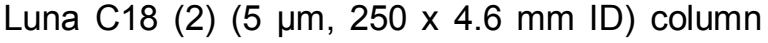
(Phenomenex, USA) fitted with a refillable guard column (Upchurch Scientific, Oak Harbour, WA, USA) packed with Perisorb RP-18 (30 - $40 \mu \mathrm{m}$, pellicular) was used for elution of salbutamol. The analysis was run at a flow-rate of $0.8 \mathrm{ml} / \mathrm{min}$. The mobile phase consisted of phosphate buffer $(\mathrm{pH} 2.5)$, methanol and acetonitrile (890:170:20, v: v: v), the excitation and emission wavelengths were $275 \mathrm{~nm}$ and $309 \mathrm{~nm}$ respectively.

\section{Statistical analysis}

Drug plasma concentration and pharmacokinetic parameters were analyzed by Wilcoxon Signed Rank test for paired samples and analysis of variance (ANOVA) at $95 \%$ confidence limit. Difference between two related means was considered statistically significant at $p \leq 0.05$.

\section{RESULTS}

\section{Characteristics of pellets}

Rapidly disintegrating pellets with good flow properties, smooth surface, a narrow particle size distribution and optimum elasticity and plasticity of the mass were obtained by combining Avicel $\mathrm{PH} 101$ and lactose in the ratio of 70:20, together with $5 \%$ drug, $3 \%$ AcDiSol, and $2 \%$ PVP K30. The yield, flow rate and mean particle size of the optimized pellet formulation were $74.65 \%, 21.63$ $\mathrm{g} / \mathrm{sec}$ and $889.6 \mu \mathrm{m}$, respectively.

\section{Formulation of hydrocolloid plug}

A total of $4 \mathrm{~h}$ lag time was intended for this pulsatile capsule. The plug was designed to provide $2 \mathrm{~h}$ lag time and the remaining $2 \mathrm{~h}$ was aimed to achieved by enteric coating. The 
formulation sealed with 10,20 and $30 \mathrm{mg}$ of sodium alginate as plug material showed lag time of $0.15 \pm 0.010 \mathrm{~h}, 1 \pm 0.15$ and $1.5 \pm 0.25 \mathrm{~h}$, respectively. At the end of $2 \mathrm{~h}, 87.98$ and 42.11 $\%$ drug release was observed from formulations plugged with 20 and $30 \mathrm{mg}$ of sodium alginate, respectively. On the basis of plug ejection time and release profile obtained, sodium alginate 20 $\mathrm{mg}$ was selected for further study.

Ethyl cellulose $(5,10$ and $15 \mathrm{mg}$ ) as a release modifier was added to replace the sodium alginate in the mixture to overcome the problem of drug leaching before the actual ejection of the plug. A plug made up of sodium alginate and ethyl cellulose $(1: 1,20 \mathrm{mg})$ was considered as optimized plug since it was able to stop drug release frompellets for the required period of $2 \mathrm{~h}$ (Fig 1).

\section{Enteric-coated plugged capsule}

In order to achieve the complete lag time of $4 \mathrm{~h}$ as indicated above, the capsule plugged with hydrocolloid material was further coated with enteric polymer. On the basis of results obtained after disintegration and dissolution analysis of various enteric polymers and their combinations in $0.1 \mathrm{M} \mathrm{HCl}$ and $\mathrm{pH} 6.8$ phosphate buffer, capsules coated with $6 \% \mathrm{w} / \mathrm{w}$ coat of a mixture of Eudragit S100 and L100 (4:1) was considered to be optimized in terms of providing a lag time to 2 $\mathrm{h}$ and a total lag time of $4 \mathrm{~h}$ (Table 1).

Animal study for developed pulsatile capsule. The limit of quantification (LOQ) was set at 5.0 $\mathrm{ng} / \mathrm{ml}$, which was the lowest concentration used in constructing the standard calibration curve. The limit of detection was $1 \mathrm{ng} / \mathrm{ml}$. Inter-day accuracy ranged between 91.28 and $102.45 \%$ with precision between 1.90 and $9.26 \%$. Intraday accuracy ranged between 89.92 and 108.11 $\%$ with precision between 0.65 and $10.24 \%$.

Drug release from the optimized time-controlled capsule was halted for a period of approximately $4 \pm 0.25 \mathrm{~h}$ with mean $\mathrm{C}_{\max }$ and $\mathrm{T}_{\max }$ of $271.54 \pm$ $58.95 \mathrm{ng} / \mathrm{ml}$ and $6.0 \pm 0.25 \mathrm{~h}$, respectively. Drug absorption from IR capsule was rapid without lag time. Mean $\mathrm{C}_{\max }$ and $\mathrm{T}_{\max }$ values obtained after administration of IR capsule were $260.35 \pm 54.19$ $\mathrm{ng} / \mathrm{ml}$ and $2.0 \pm 0.25 \mathrm{~h}$, respectively. The $\mathrm{AUC}_{0-\infty}$ of salbutamol after administration of timecontrolled pulsatile system was $2494.73 \pm 525.95$ $\mathrm{ng} \mathrm{h} / \mathrm{ml}$ while that of the immediate release formulation was $2352.77 \pm 432.51 \mathrm{ng} \mathrm{h} / \mathrm{ml}$. There was a statistically significant difference $(p \leq 0.05)$ between the $T_{\max }$ values of the two formulations. However, there was no significant difference $(p \leq 0.05)$ in $C_{\max }$ and $A \mathrm{CC}_{0-\infty}$ values between the two formulations (Fig 3 ).

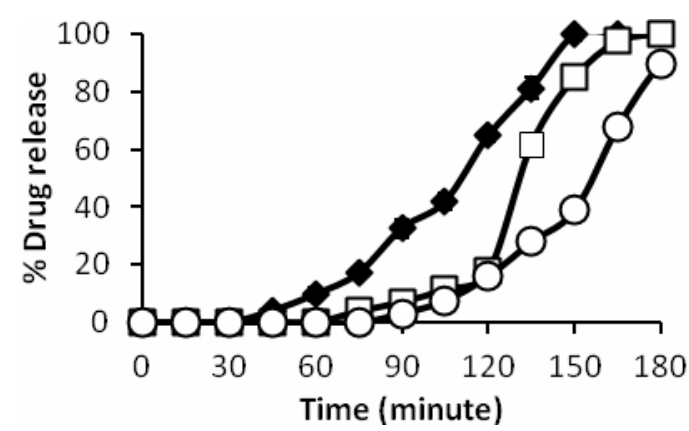

Fig 1: In vitro release profile of pulsatile capsule plugged with various amounts of ethyl cellulose (EC) and sodium alginate (SA) mixture; $\bullet=15 \mathrm{mg}$ SA and 5 $\mathrm{mg} \mathrm{EC}, \square=10 \mathrm{mg} \mathrm{SA}$ and $10 \mathrm{mg} \mathrm{EC}, 0=5 \mathrm{mg} \mathrm{SA}$ and $15 \mathrm{mg} \mathrm{EC}$

Almost $97.65 \%$ drug was released in $\mathrm{pH} 6.8$ in a period of $2.25 \mathrm{~h}$ (Fig 2).

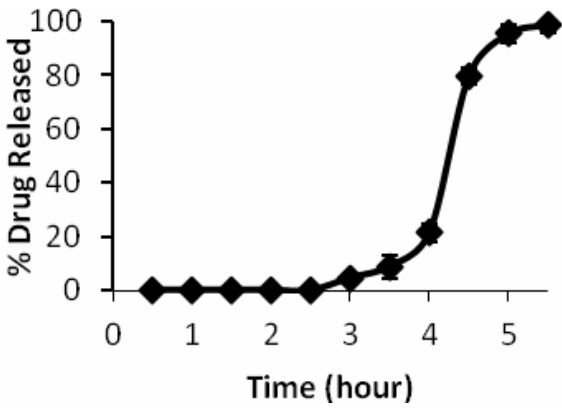

Fig 2: Dissolution profile of optimized dosage form in $0.1 \mathrm{M} \mathrm{HCl}$ (initial $2 \mathrm{~h}$ ) and then in $\mathrm{pH} 6.8$ phosphate buffer.

Table 1: Effect of disintegration and dissolution on formulations of various combinations of Eudragit $S 100$ and $L$ 100 with various levels of enteric coating

\begin{tabular}{|c|c|c|c|c|c|c|c|c|c|c|c|c|c|c|c|}
\hline Parameter & & S1 & & & L 10 & & & $\llcorner 100$ & $(1: 1)$ & & 0:L10 & $0(2$ & $\mathbf{S 1 0}$ & $\llcorner 100$ & $(4: 1)$ \\
\hline Coating level (\% w/w) & 4 & 6 & 8 & 4 & 6 & 8 & 4 & 6 & 8 & 4 & 6 & 8 & 4 & 6 & 8 \\
\hline Disintegration test & $\mathrm{F}$ & $P$ & $P$ & $\mathrm{~F}$ & & & $\mathrm{~F}$ & $P$ & $P$ & $\mathrm{~F}$ & $P$ & $P$ & $\mathrm{P}$ & $P$ & $P$ \\
\hline $\begin{array}{l}\text { Solubility in } \mathrm{pH} 5.5 \\
\text { Avg. lag time in } \mathrm{pH} 6.8 \text { (h }\end{array}$ & $\begin{array}{l}-- \\
--\end{array}$ & $\begin{array}{l}S \\
1.3\end{array}$ & $\begin{array}{l}\text { NS } \\
2.8\end{array}$ & $\begin{array}{l}-- \\
--\end{array}$ & $\begin{array}{l}S \\
1.3\end{array}$ & $\begin{array}{l}S \\
1.3\end{array}$ & $\begin{array}{l}- \\
--\end{array}$ & $\begin{array}{l}S \\
1.3\end{array}$ & $\begin{array}{l}S \\
1.8\end{array}$ & $\begin{array}{l}- \\
-\end{array}$ & $\begin{array}{l}S \\
1.3\end{array}$ & $S$ & $\begin{array}{l}S \\
1.9\end{array}$ & $\begin{array}{l}\text { NS } \\
2.0\end{array}$ & $\begin{array}{l}\text { NS } \\
2.3\end{array}$ \\
\hline
\end{tabular}

$F=$ Failed, $P=$ Passed,$S=$ Soluble, $N S=$ Not soluble. 


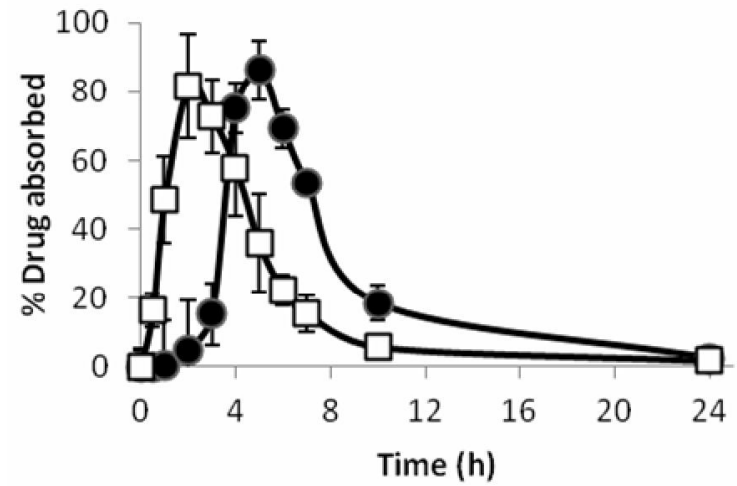

Fig 3: Comparative plasma drug concentration vs. time profiles of immediate release $(\square)$ and pulsatile capsules $(\bullet)$ of salbutamol sulphate

\section{DISCUSSION}

The developed system is based on the combination of $\mathrm{pH}$ sensitive (enteric) coating and time-controlled (plug) delivery.

Schiff's base condensation phenomenon has been employed to modify the solubility of gelatin capsule bodies. On exposure to formalin vapors, amino group present in the gelatin (capsule shell) molecular chain undergoes cross linking with aldehyde group present in formaldehyde molecule as per Schiff's base condensation resulting in decreased aqueous solubility of gelatin [11]. The present study revealed that Avicel $\mathrm{PH} 101$ in combination with lactose formed pellets with smooth surface characteristics. With increase in lactose concentration, a decrease in the yield, increase in friability and generation of fines were observed. At increased Avicel PH 101 content, mean particle diameter decreased and most pellets formed were spherical with even particle size distribution. Since sodium alginate has lower mechanical strength and is sticky, the plug was completely detached from the capsule, leading to complete and immediate release after the desired lag period [12].

A $6 \%$ w/w coat of Eudragit S100 and L100 in ratio of $4: 1$ was found to be optimum since the coat was intact after $2 \mathrm{~h}$ disintegration analysis in $0.1 \mathrm{M} \mathrm{HCl}$ which indicates the ability of the coat to withstand gastric acid conditions. During dissolution studies it was observed that the coat was completely dissolved in $\mathrm{pH} 6.8$ which confirms the release of the drug in the duodenum part specified region of small intestine to maintain the desired lag time of $2 \mathrm{~h}$. The soluble cap of the capsule had dissolved completely after 15-20 min and thus exposed the polymer plug which absorbed the surrounding fluid, swelled and released the drug through the swollen matrix. Following complete wetting of the plug, it formed a soft mass which was then easily ejected out of the capsule body by erosion mechanism, thus releasing the pellets into the medium which readily dissolved and complete drug release was achieved after a lag time of $4.25 \mathrm{~h}$.

There was statistically significant difference between the $T_{\max }$ values of the two formulations. However, there was no statistical significant difference between the two formulations with regard to $\mathrm{C}_{\max }$ and $\mathrm{AUC}_{0-\infty}$ values. The in-vitro results are supported by the in vivo data in terms of the drug release and lag time obtained.

\section{CONCLUSION}

The in vivo study supports the capability of the developed pulsatile release system to delay drug release in the gastrointestinal tract after 4-h lag time. Thus, the developed capsule-based delivery system can be considered a promising formulation for time-controlled delivery of salbutamol for the nocturnal management of asthma.

\section{ACKNOWLEDGMENT}

The authors are thankful to University Grants Commission of India for providing financial assistance to carry out this work.

\section{REFERENCES}

1. Maroni A, Zema L, Cerea M. Site and time specific oral drug delivery Expt Opinion Drug Del 2005; 2: 855871.

2. Pozzi F, Furlani P, Gazzaniga A, Gastro retentive drug delivery system is an approach to achieve improved therapeutic efficacy. J Control Rel 1994; 3: $99-108$.

3. Youan BC Chronopharmaceutics: gimmick or clinically relevant approach to drug delivery. J Control Rel 2004; 98(4): 337-353.

4. Siegel RA, PittCG. A Strategy for Oscillatory Drug Release: General Scheme and Simplified Theory, J Control Rel 1995; 33: 173-188.

5. Pincus DJ, Beam WR, Martin RJ. Chronobiology and chronotherapy of asthma. Clin Chest Med 1995; 16(4): 699-713.

6. Vianna EO. Mechanisms and Therapeutic Implications of Asthma Circadian Rhythm. Curr Resp Med Rev 2005; 13: 171-183.

7. J Qureshi MJ, Ali J, Baboota S, Ahuja A, Mallikarjun C. Development and Evaluation of Chronotherapeutic Drug Delivery System for the Management of Nocturnal Asthma. Trop J Pharm Res 2012; 11(5): 703-712

8. Lin $\mathrm{JH}$. Applications and limitations of interspecies scaling and in vitro extrapolation in pharmacokinetics. Drug Metab Dispo 1998; 26: 1202-1212.

9. Kapalan SA, Jack ML. Principles and perspectives in drug bioavailability. In: Blanchard J, Sawchuk RJ, Brodie BB (Eds). Basel, New York: Karger, 1979; $p$ 156. 
10. Guide for the care and use on laboratory animals. $8^{\text {th }}$ edition, 2011 National academic press, Washington DC. 20001

11. Xiao-Li DU, Zhu Z, Qiang FU, Da Kui LI, Wen-Bing XU. Pharmacokinet ic and relative bioavailability of salbutamol metered-dose inhaler in healthy volunteers. Acta Pharmacol Sin 2004; 23(7): 663666
12. Philip AK, Philip B. Phase transited and vapor-induced dual capsular system (DCS) for achieving delayed and osmotic release of cefadroxil. Pharm Dev Tech 2010; 1-913Roy P, Shahiwala AA. Multiparticulate formulation approach to pulsatile drug delivery: C12urrent perspectives. J Control Rel 2009; 134: 74-80. 